\title{
Improving Overall Equipment Effectiveness (OEE) of Extrusion Machine Using Lean Manufacturing Approach
}

\author{
Tamer Haddad ${ }^{1}$, Basheer W. Shaheen², István Németh ${ }^{2}$ \\ ${ }^{1}$ Department of Industrial Engineering, An-Najah National University, Nablus, Palestine. E-mail: t_had- \\ dad@najah.edu \\ ${ }^{2}$ Department of Manufacturing Science and Engineering, Budapest University of Technology and Econom- \\ ics, 1111 Budapest, Műegyetem rkp. 3, Hungary. E-mail: Shaheen@manuf.bme.hu, inemeth@ma- \\ nuf.bme.hu
}

Providing products with higher quality and lower prices is considered to be a competitive advantage for the industrial firms over competitors. This main challenge can be achieved by minimizing the overall production costs and operational time. Lean manufacturing provides many tools and techniques to identify and eliminate wastes and to reduce costs in production systems. In this paper, the single minute exchange of die (SMED) technique is used as a lean manufacturing approach in a leading Palestinian aluminum and profiles company. SMED was implemented through real experimental procedures applied to the extrusion line processes to investigate its effect on decreasing the setups time and improving the Overall Equipment Effectiveness (OEE) of the extrusion machine, in addition to introduce a guide for practitioners to improve the extrusion process of dies exchange in similar industries. Overall, the successful implementation of SMED resulted in an increase of OEE by $3.26 \%$ as the consequence of the increase of machine availability by $4.86 \%$.

Keywords: Overall Equipment Effectiveness (OEE), Single Minute Exchange of Die (SMED), Lean, Availability, Extrusion.

\section{Introduction}

Due to the increasingly competitive environment nowadays, industrial companies have to meet customers' requirements in terms of quality, cost, flexibility, and delivery times. Thus, companies should have strategies to make their processes more flexible and efficient [1]. In addition, to focus on reducing the overall production costs, achieving higher profitability, increasing the productivity and the efficiency of manufacturing processes at the same time [2]. Therefore, all processing times and operations need to be managed and evaluated in a good manner through specific assessment tools to achieve a stable and reliable workflow to boost and sustain the overall performance [3]. The primary motivation is to test these strategies to eliminate waste in processes through the implementation of lean principles [4]. Thus, lean manufacturing tools are widely used to reduce wastes in processes, decrease the required processing times, and increase performance, quality, delivery and productivity KPIs and the value of products [5]. Lean principles help companies to develop their core competencies by eliminating all non-value added activities that lead to a reduction in manufacturing costs, lead time, setup/changeover time, and to develop team-based work organizations [6] [7] [8]. Among lean manufacturing tools, single minute exchange of dies (SMED) is considered an efficient tool to reduce the changeover times or machine setups by converting the steps that are being done while the machine is stopped (internal activities) into steps that can be done while the machine is operating (external activities) [9].

The aim of this paper is to apply SMED in an aluminum extrusion line through real experimental procedures and investigate the effect of applying such a strategy on decreasing the setup time of the dies exchange of an extrusion machine. Consequently, improving the overall equipment effectiveness (OEE) of the machine. In addition to this, this paper suggests practical actions to improve the process of dies' exchange.

The industrial partner, subject of this study, is a leading Palestinian aluminum and profiles company founded in 1991 to serve the local market needs of Aluminum profiles. The annual production capacity of the company is about 7,000 tons of high-quality products that comply with national and international standards and specifications. According to its strategic plans, the company seeks to develop the production lines and labor skills to enhance its core competencies. This work is based on the high-level cooperation between academic institutions and industry (win-win 
cooperation).

\section{SMED and OEE Overview}

In order to adopt a productivity-oriented strategy, the most important step is to identify and analyze the processes and the effects of the potential downtimes on production efficiency. For this purpose, different indicators related to the performance and the productivity of the manufacturing system should be determined. According to [9], the most widely used performance indicator is the OEE that consists of three main elements: availability, performance, and quality [10]. Consequently, OEE can be calculated according to equation (1):

$$
\text { OEE }(\%)=\text { Availability } \times \text { Performance } \times \text { Quality } \times 100 \%
$$

OEE can be considered as an excellent indicator to measure the achieved sustainability improvement compared to the initial state of the company's processes [11]. Moreover, OEE is a key performance indicator of a machine or a system. It can also give insights into the performance of the personnel who are responsible for maintaining the system. Based on this performance measure, the focus must be on downti- mes/failures, which have a high impact on the availability and the operational efficiency or product quality.

Availability is calculated based on the operating time and downtime loss. Performance is calculated based on net operating time and speed loss, whereas quality is calculated based on fully operative time and quality loss. According to Domingo and Aguado [11], these three OEE elements can be calculated as follows:

$$
\begin{gathered}
\text { Availability }=\frac{(\text { Total time available }- \text { Downtime })}{\text { Total available time }} \\
\text { Performance }=\frac{\text { Number of units produced }}{\text { Possible number of units }} \\
\text { Quality }=\frac{(\text { Number of units produced }- \text { Number of defects })}{\text { Number of units produced }}
\end{gathered}
$$

Similarly, to obtain maximal availability, an essential task is to identify the potential root causes of downtime and prevent or mitigate them [10]. The availability factor is perhaps the most crucial index in OEE calculation, as it also affects performance. If the manufacturing system is not available, we cannot produce any unit, but the possible number of units remains the same, so performance drops dramatically. The possible number of units can be the maximum capacity of the production system or the number of items to be manufactured if it is less than the capacity. The quality of produced units is essential as malfunctional manufacturing equipment also decreases the OEE of the system.

The method of single minute exchange of die (SMED) was developed by the Japanese engineer Shigeo Shingo, and it is considered as one of the lean manufacturing techniques that aim to analyze and reduce setup times; the setups can be reduced from hours to minutes [12]. SMED is usually used to reduce changeover time and setups, which are considered as forms of waste in the lean concept, and they should be minimized or eliminated by replacing the setting time of internal activities (performed during machine stoppage) to external activities time (performed while the machine or equipment is running) [13]. In addition, SMED provides a quick changeover to reduce the time spent in the setups, which is considered a waste, causing a significant increase in manufacturing costs. Machine changeovers refer to any planned modification made to it, for example, die or tool change, change of packaging material, product change, and reference change in production [14]. The phrase "Single Minute" does not mean that all changeovers and setups should take only one minute or less, but they should take less than 10 minutes if possible (i.e., "Single Digit Minute") [12].

Reducing the setup time leads to increased productivity of the equipment and that of the manufacturing systems due to the efficient reduction of setup time for tool changeover, which leads to an increase in the availability of the equipment. The key of SMED is the rapid changeover of the tool, which reduces the lot sizes, improves the flow, and increases the efficiency of the equipment and the productivity of the system as well.

\section{Study Objectives and Methodology}

In this study, the SMED approach is implemented through experimental procedures in the targeted company as a real problem solver. The aim is to decrease the setup time of extrusion dies changeover and investigate its effect on raising the OEE of the extrusion machine by increasing productivity, and hence, enhancing the efficiency of the overall production systems. 
The work was initiated by conducting a literature review in order to get the required knowledge about the SMED approach, OEE, and related measures. In addition, the relationship between SMED and OEE was investigated for better understanding.

The verification of the existing production process and die exchange process activities was done through field observations and interviews with the production line engineers and staff. All activities were sorted external or internal according to the SMED approach. The validation was carried out through data collection; each activity period during the changeover was recorded using a stopwatch before and after the SMED implementation. Then, the gathered data was analyzed, and the effect of applying the SMED methodology was calculated to check if it enhances the value of the OEE of the machine. More details are available in the following sections where this work can be considered as a guide for practitioners.

\section{Literature Review}

Many research studies focused on increasing the OEE of various equipment and manufacturing systems using different lean manufacturing tools by decreasing the setup times, reducing the changeover time, increasing the availability. Chong et al. [15] used the Failure Mode and Effects Analysis (FMEA) to improve the OEE in a semiconductor manufacturing company by focusing on the bottleneck of the die bonding process. The results of the FMEA analysis provided a list of corrective actions along with their priority of implementation, which led to improve the OEE of the targeted equipment.

Mulla et al. [16] implemented SMED on a vertical boring machine to improve its OEE and eliminate the existing delays in delivery; changeover times were measured before and after implementing the SMED. The successful implementation of SMED resulted in a $31.25 \%$ reduction of changeover time (from 160 to 110 minutes). Another similar recent study was conducted by Sousa et al. [17] on an assembly machine of cork stoppers production. SMED was applied to reduce the downtime caused by the tool changes. As a result, a reduction of $43 \%$ in total changeover time was achieved. Then OEE was calculated to understand the impact of the applied improvements.

Moreover, SMED methodology was also used in the food industry to measure the results of SMED implementation through different key performance indicators. Lozano et al. [18] used Mean Time between Failure (MTBF), Mean Time to Repair (MTTR), Global Efficiency (GE), and OEE as key performance indicators. The SMED implementation focused on analyzing the possible irregular losses of a packaging machine changeover, such as lack of standard work methodology, maintenance defects, lack of spare parts, and lack of operator specialization.

Implementing the SMED methodology allows the changeover and setup process to be standardized, and hence, any unnecessary time spent during setup can be reduced. Otero and Lopes [19] reduced the changeover total time in a final assembly line that produces automotive instrument panels using the SMED methodology. It became a simple and organized changeover process. For this purpose, standard work instructions, tables, and charts were developed. As a result, 33.8 minutes reduction of the total changeover time was obtained; this time was approximately 59\% of the initial changeover time. The SMED technique in manufacturing can eliminate the small stop time loss that has been regarded as one of the most challenging losses to be reduced [20]. Applying this technique plays a vital role in tackling the losses and improving the value of OEE. Jebaraj Benjamin et al. [20] used this technique in a metal barrel manufacturing company. The SMED technique was extended to eliminate one of the big losses, namely the small stops, instead of only the setup and changeover. This new application resulted in a valuable $2.08 \%$ improvement in the company's OEE.

Furthermore, SMED was used to improve OEE in the automotive industry. Rasib et al. [2] applied the SMED to enhance the production efficiency in an automotive company; the results of the implementation indicate improvement of the overall productivity and the OEE rate of the manufacturing line. Similarly, SMED was used by Macedo Fraiz et al. [21] as a lean tool to reduce the lead time and improve the OEE in a manual process as a result of increasing the availability in an oil and gas sector company. SMED implementation resulted in a significant reduction in the setup time and shortened the operators' total traveling distance when doing manufacturing activities.

Changeover activity is critical in organizations that produce a large number of products that should be minimized in order not to reduce productivity. Syafei and Lokadipati LS [13] used SMED methodology to reduce setup and clean up times in a drying room in the pharmaceutical industry. They managed to combine 43 internal activities up to 11 activities. As a result, a setup time and clean up were decreased by $62.18 \%$, which could increase the production line productivity. Tamás in [22] investigated the possibilities of setup time reduction in in production logistics using applications of simulation modelling using SMED approach.

SMED should be combined with other lean tools such as 5S, standardized work, kaizen, overall equipment efficiency, total productive maintenance, pokayoke, value stream mapping, and visual management according to da Silva and Godinho Filho [23]. Likewise, the SMED tool was used effectively to improve quality and on-time delivery performance to satisfy 
customers. Gabahne et al. [24] used SMED, total productive maintenance (TPM), and $5 \mathrm{~S}$ to improve the OEE of the bottleneck machine in an injection molding process. The process has large variability that negatively affects customers' satisfaction and high costs in terms of work in progress, inventory, and rework. As a result, a $5 \%$ improvement in OEE was gained, and the firm's annual earnings were increased through improving availability and performance.

Typically, SMED and other lean tools were also used in the packaging of pharmaceutical products due to the importance of protecting products from physical, biological, and chemical damage. Bevilacqua et al. [25] used SMED to eliminate non-added value activities and standardize the changeover and setup procedure by reducing internal activities considering the constraints of the pharmaceutical industry. SMED was used in integration with other lean tools such as KANBAN, 5S, and TPM to optimize and reduce variability in changeover times, increasing the packaging capacity and improving the OEE by $25 \%$. HuarhuaMachuca et al. [26] proposed a combination of 5S and SMED to reduce the number of production defects in an electrode manufacturing company using simulation. This proposal reduced the number of defectives by $11.23 \%$, thus, improving the level of quality and yielding economic benefits.

\section{The Case Study}

\subsection{Main Characteristics of the Extrusion Production Line}

The production process starts by using aluminum logs of 7 inches in diameter (raw material). After being heated up to $480{ }^{\circ} \mathrm{C}$, the aluminum billets become ready to be extruded through the die to produce different forms of aluminum profiles using a 7000 tons annual capacity of the extrusion hydraulic press. There are two types of dies: the flat dies produce flat profiles, and the hollow dies produce hollow profiles with different dimensions, as shown in Table 1.

Tab. 1 Extrusion dies dimensions

\begin{tabular}{ccc}
\hline Die Type & Thickness $(\mathrm{mm})$ & Diameter $(\mathrm{mm})$ \\
\hline Flat & 120 & 225 \\
Hollow & 160 & 250 \\
\hline
\end{tabular}

The main characteristics of the extrusion production line can be summarized by the total number of working days per month, which is about 24 days. Each working day has 24 hours of continuous production achieved through three 8-hour shifts. On the other hand, the planned downtime for preventive maintenance is about 2 hours per week, while the average number of die changeover is 13 per day to produce an average volume of 18.36 tons per day of extruded aluminum profiles with an average daily amount of scrap (waste) of 0.716 ton.

\subsection{Analysis of the Die Changeover Process}

Before applying the SMED, the die changeover process was composed of the stages shown in Figure 1. First, the extrusion machine is shut down, and the die slide is opened to change the die. The old die (the previously used die) is totally removed, and an insert is put in the die slide to facilitate setting up the new die (next die to be used). The intended die is then brought from the furnace with a crane and inserted instead of the old one. Finally, the die slide is closed again to test the new die installation to ensure that the process produces products complied with the technical specification.

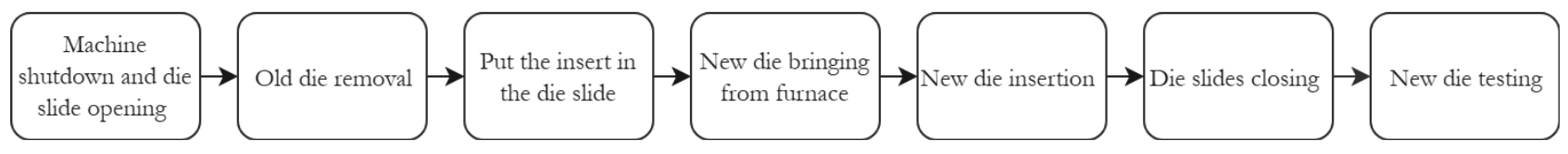

Fig. 1 Extrusion die changeover process before SMED implementation

\section{SMED Implementation}

SMED is considered as an important lean manufacturing tool used to reduce setup and change over time, which has a direct impact on the availability and OEE of the manufacturing machines and equipment, which also affects the overall productivity of the production line [27]. The methodology to implement SMED on the extrusion processes was adopted according to [28]. The implementation process needs a previous analysis to clearly understand the changeover process and every single detail of the overall process [29].
Shingo [12] classified the operations in any manufacturing process as internal and external. Internal operations can only be performed while the machine is stopped, and external operations can be performed while the machine is still operating. Therefore, the application of the SMED methodology consists of four stages. Preliminary Stage (Stage 0), in which the internal and external setup stages are not differentiated; here, the processing steps must be understood, observed, and measured. A video recorder and a stopwatch were used to record and measure the consumed time of each step. Then Stage 1 comes to separate the external and internal setup. For more convenience, a 
checklist - including step name, specifications, location, auxiliary tools needed, and the measured values - has been developed to collect and classify all this information preparing to split the external setup steps from the internal ones. Stage 2 aims to convert the internal setup activities to external. Before going through this stage, an evaluation of the transportation equipment used to move the die is required to investigate the possibilities of reducing the needed time to move spare parts and other components before embarking on the actual setup steps. Setup time reduction usually provides many benefits such as reduction of stock, work in progress, batch size, and movements,

as well as improvement in quality and production flexibility [30]. Lastly, Stage 3 of the SMED methodology is about rationalizing the internal and external setup for better replacement and time reduction solutions.

\section{Results and discussion}

\subsection{Data collection and analysis}

Cause and effect diagram was used to identify the possible causes for the long changeover time of the extrusion machine dies as depicted in Figure 2. This type of analysis assists in identifying the root causes of the problem and generating proper solutions to such problems.

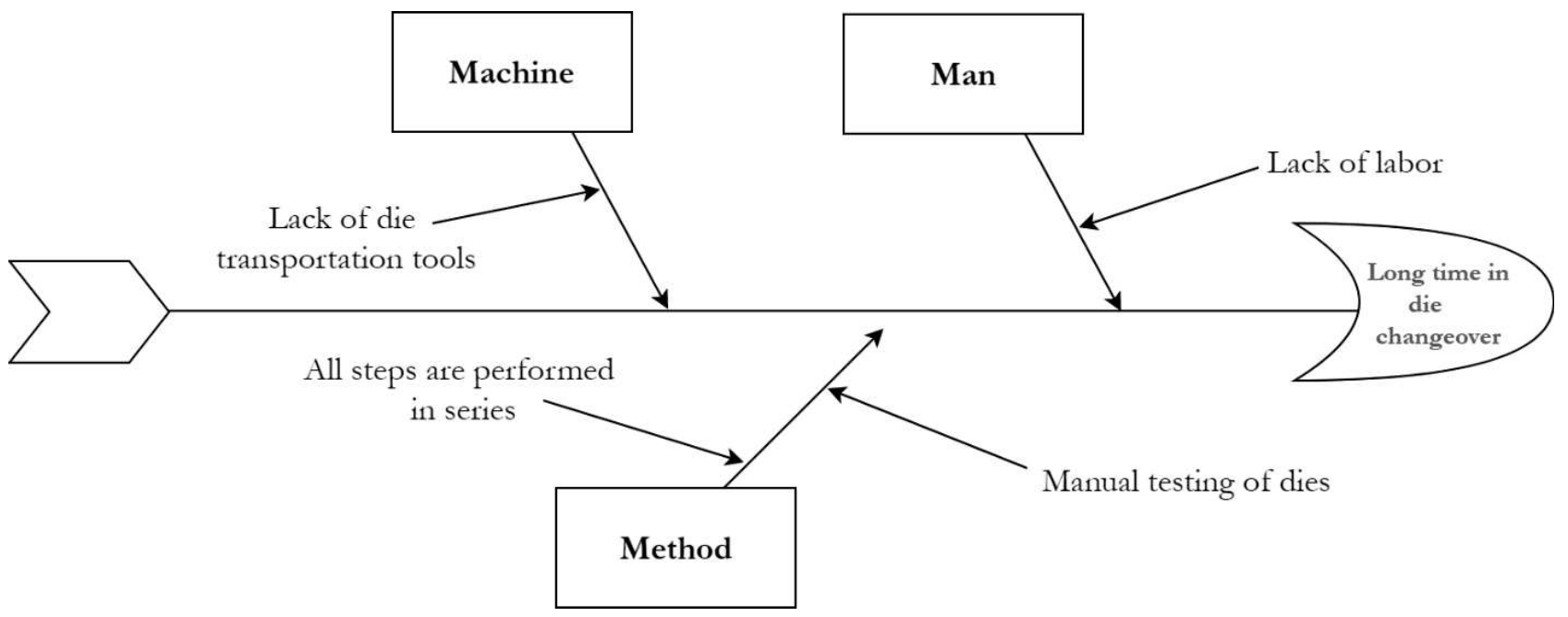

Fig. 2 Cause-and-effect diagram of long changeover time

Preliminary verification of the aluminum profiles extrusion line was carried out to be introduced to all processes and classify them into internal and external; this was achieved by observing the processes and conducting interviews with production engineers and related staff. Before applying the SMED technique, the die changeover time was measured and recorded for each sub-process and for the overall changeover, as shown in Table 2 below. For more accuracy, the recorded time for each step is the average time for 3 consequent readings, considering the unexpected uncertainty during measurement.

Tab. 2 Changeover time before SMED implementation - processes verification

\begin{tabular}{|c|c|c|c|c|}
\hline Step No. & Description & $\begin{array}{c}\text { Classification (Inter- } \\
\text { nal/External) }\end{array}$ & $\begin{array}{c}\text { Average time (sec- } \\
\text { onds) }\end{array}$ & $\begin{array}{c}\text { The ability to be con- } \\
\text { verted to external }\end{array}$ \\
\hline 1 & $\begin{array}{l}\text { Machine shutdown } \\
\text { and die slide opening }\end{array}$ & Internal & 17.2 & No \\
\hline 2 & Old die removal & Internal & 37.2 & No \\
\hline 3 & $\begin{array}{l}\text { Put an insert in the } \\
\text { die slide }\end{array}$ & Internal & 38.8 & No \\
\hline 4 & $\begin{array}{l}\text { New die bringing } \\
\text { from furnace }\end{array}$ & Internal & 61.7 & Yes \\
\hline 5 & New die insertion & Internal & 12.6 & No \\
\hline 6 & Die slide closing & Internal & 25.8 & No \\
\hline 7 & New die testing & Internal & 346.0 & Yes \\
\hline
\end{tabular}

Total time

$539.3 \mathrm{sec}(8.99 \mathrm{~min})$ 
From Table 2, the average changeover time is 539.3 seconds $(8.99 \mathrm{~min})$ that is the sum of all steps' times. To be able to calculate the OEE before applying the SMED, all components of the OEE were calculated according to equations (2), (3), and (4). Based on the information that the average daily number of changeovers is 13 and the weekly scheduled downtime is 2 hours, the OEE is computed as follows:

- Total available time $=(312$ day $/$ year $) \times(24$ hours $/$ day) $=7,488$ hours $/$ year

- Total scheduled downtime per year $=(2$ hours $/$ week $) \times(52$ week $/$ year $)=104$ hours

- Total changeover time per year $=(0.15$ hours/change $) \times(13$ changes/day $) \times(6$ days $/$ week $) \times(4$ weeks $/$ month $) \times(12$ month $/$ year $)=607.61$ hours

- Availability $=[(7,488-104-607.61) / 7,488]$ $\times 100 \%=90.50 \%$

- Average production per hour $=765 \mathrm{~kg} /$ hours

- Average scrap per day $=716.16 \mathrm{~kg}$

- Total production per year $=(765 \mathrm{~kg} /$ hour $) \times$ $(24$ hours/day $) \times(6$ days/week $) \times(4$ weeks $/$ month $) \times(12$ month $/$ year $)=5,287.68$ ton/year

- Total scrap per year $=(716.16 \mathrm{~kg} /$ day $) \times(6$ days $/$ week $) \times(4$ weeks $/$ month $) \times(12$ month $/$ year $)=223.44$ ton $/$ year

- Quality $=[(5,287.68-223.44) / 5,287.68] \times$ $100 \%=95.77 \%$
- Performance $=[5,287.68 / 7,000] \times 100 \%=$ $75.54 \%$

Then, the OEE $=90.50 \% \times 95.77 \% \times 75.54 \%=$ $65.47 \%$.

\subsection{SMED implemented procedures}

Applying the SMED technique is based on separating the internal and external changeover activities and converting internal steps to external ones as much as possible or combining steps to eliminate unnecessary waste in changeover time. Table 2 shows that all changeover activities are internal as all are performed while the extrusion machine is stopped.

Before implementing improvement actions, two proposals were made to increase the OEE. The first proposal is to combine steps 2,3 , and 4 as in Table 2 by allocating additional operators and using another crane to bring the new die while removing the old one. This solution converts step 4 from internal to external as it can be done while the machine is still working. The second proposal is to install a new automated polishing machine instead of doing the polishing process manually. This proposal decreased the time required to test the new die before the machine is fully operational.

In conclusion, both proposals reduced the changeover time from 8.99 to 3.88 minutes, which improved and increased the process availability from $90.50 \%$ to $95.36 \%$ (see calculations below). Figure 3 shows the die changeover process after implementing SMED. The die changeover time after implementing the abovementioned solutions is given in Table 3 .

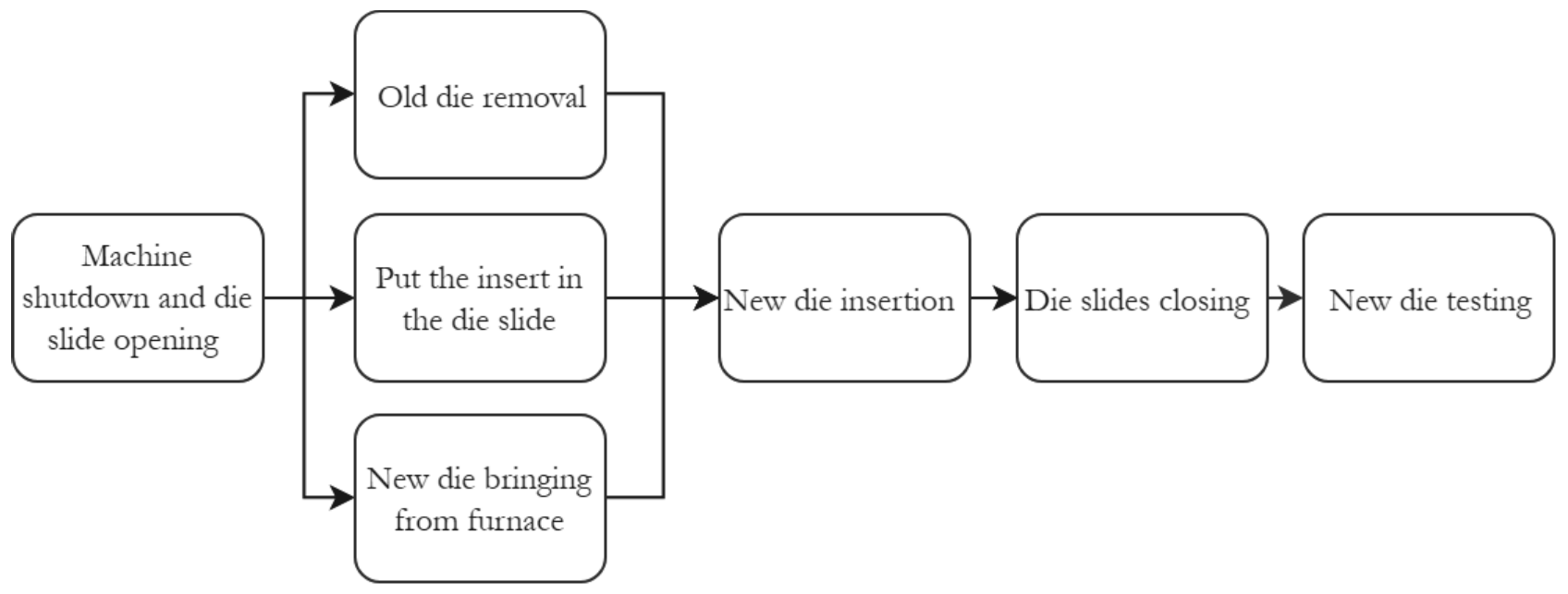

Fig. 3 Extrusion die changeover process after SMED implementation

The proposed two solutions have reduced the average changeover time by $5.11 \mathrm{~min}$ to $3.88 \mathrm{~min}$ per die change. The new value of OEE for aluminum extrusion production line die exchange after implementing the SMED technique is computed as follows:

- Total changeover time per year $=(0.065$ hours/change $) \times(13$ changes/day $) \times(6$ days $/$ week $) \times(4$ weeks $/$ month $) \times(12$ month $/$ year $)=243.36$ hours

- $\quad$ Availability $=[(7488-104-243.36) / 7488] \times$ $100 \%=95.36 \%$ 
Then, $\mathrm{OEE}=95.36 \% \times 96.09 \% \times 75 \%=68.73 \%$.

This increase in OEE came from improving the availability indicator. SMED implementation raised the availability to $95.36 \%$ with an increase of $4.86 \%$, leading to an increase in the OEE by $3.26 \%$. Figure 4 shows the change in the changeover process in terms of availability and OEE before and after implementing the SMED approach.

Tab. 3 Changeover time after application of SMED

\begin{tabular}{|c|c|c|c|c|}
\hline $\begin{array}{l}\text { Step } \\
\text { No. }\end{array}$ & Description & $\begin{array}{l}\text { Improvement } \\
\text { activity }\end{array}$ & $\begin{array}{l}\text { New time } \\
\text { (seconds) }\end{array}$ & $\begin{array}{l}\text { New classifi- } \\
\text { cation }\end{array}$ \\
\hline 1 & $\begin{array}{l}\text { Machine shutdown } \\
\text { and die slide open- } \\
\text { ing }\end{array}$ & & 17.2 & Internal \\
\hline $2+3+4$ & $\begin{array}{l}\text { Old die removal }+ \\
\text { insert put in die } \\
\text { slide }+ \text { bringing the } \\
\text { new die }\end{array}$ & $\begin{array}{l}\text { Adding an- } \\
\text { other crane }\end{array}$ & 61.9 & $\begin{array}{l}\text { Bringing } \\
\text { new die be- } \\
\text { comes exter- } \\
\text { nal and per- } \\
\text { formed in } \\
\text { parallel }\end{array}$ \\
\hline 5 & New die insertion & Internal & 12.6 & Internal \\
\hline 6 & Die slide closing & Internal & 25.8 & Internal \\
\hline 7 & New die testing & $\begin{array}{l}\text { Using auto- } \\
\text { mated Prepa- } \\
\text { ration (polish- } \\
\text { ing) technol- } \\
\text { ogy }\end{array}$ & 115.3 & Internal \\
\hline & Total time & \multicolumn{3}{|c|}{$232.8 \mathrm{sec}(3.88 \mathrm{~min})$} \\
\hline
\end{tabular}

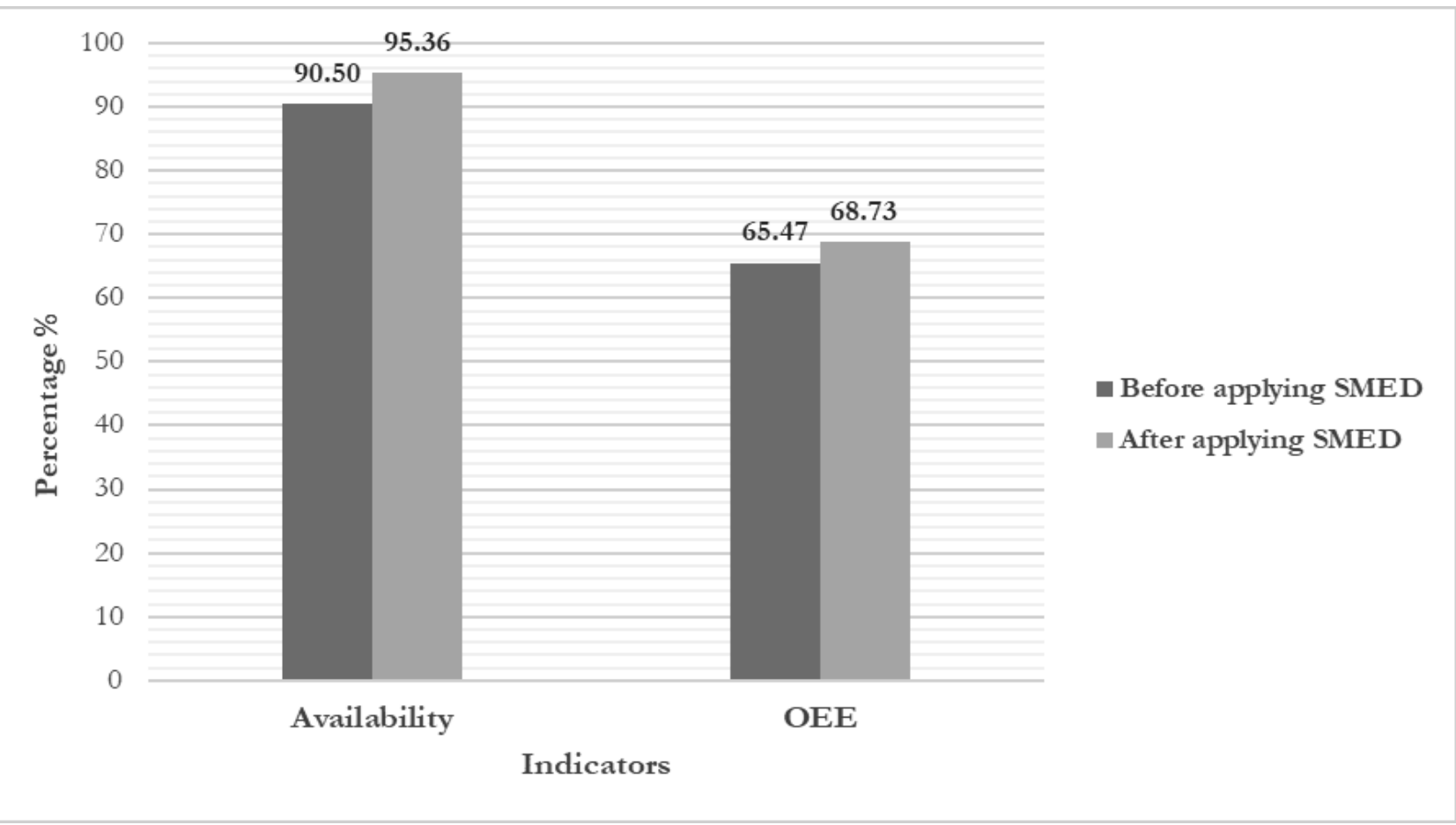

Fig. 4 Comparison - Availability and OEE before and after applying the SMED

The OEE of this extrusion process is calculated on the assumption that all other variables are constant except availability. The production line was running more smoothly after implementing the approved solutions. There is no stoppage to wait for the new die to be transported from the furnace. The OEE improvement of $3.26 \%$ is a significant achievement for the company. The new obtained value of OEE from the calculated results is still far below the world-class target of at least $85 \%$, according to Chand and Shirvani [31]. From the results of observations and data processing that were carried out in this study, the achieved OEE is still low due to the low performance of the process since the production line is not working 
at full capacity, which means that the performance indicator is $75.54 \%$.

\section{Conclusion}

The SMED technique has been proven to be an effective lean approach in tackling the downtime loss of the extrusion die changeover process. The reduction of the unproductive time has resulted in a valuable $3.26 \%$ improvement in the OEE of the extrusion machine of the company. Additional improvement beyond the achieved level requires extensive analysis and more investment. The company is fully aware of the challenges of further improvement of the OEE.

This study can be considered strong evidence of how powerful the SMED technique is by decreasing the losses in the setup process. Thus, the company has achieved an improvement in the OEE of the extrusion production line, which can increase the reliability of the processes, increase the stability of the production plans, and obtain financial gain as cost-saving.

Since the company claims that it has a total cost of 700 USD per hour that represents labor salaries, electrical power consumption and equipment depreciation. This successful application of the SMED technique can result in a total saving of around 218,400 USD per year that can be invested in further improvement projects in the future to hit the world-class target of $85 \%$ OEE.

Although this research work is limited to the selected industry, production line type and size, and the available production technologies, these changes and improvements could be considered when applying this methodology to other similar manufacturing companies in other locations and industries.

\section{Acknowledgment}

We gratefully thank the Palestinian aluminum and profiles' company for providing us with the necessary data to complete this work successfully.

\section{References}

[1] R. GODINA, C. PIMENTEL, F. J. G. SILVA, J. C. O. MATIAS (2018). A Structural Literature Review of the Single Minute Exchange of Die: The Latest Trends, in Procedia Manufacturing, 2018.

[2] A. H. A. RASIB, Z. EBRAHIM, R. ABDULLAH, Z. F. M. RAFAAI (2019). Improvement of Overall Equipment Effectiveness through Application of Single-Minute Exchange of Die in Automotive Manufacturing," Test Engineering and Management, vol. 81, pp. 3650-3659, 2019.
[3] S. JAIN, K. P. TRIANTIS, S. LIU (2011). Manufacturing performance measurement and target setting: A data envelopment analysis approach, European Journal of Operational Research, vol. 214, no. 3, pp. 616-626, Nov. 2011.

[4] A. K. SAHOO, N. K. SINGH, R. SHANKAR, M. K. TIWARI (2008). Lean philosophy: Implementation in a forging company, International Journal of Advanced Mamufacturing Technology, 2008.

[5] M. SAGAN (2018). Importance of holistic approach of assembly production transformation in manufacturing with value stream mapping, Manufacturing Technology, vol. 18, no. 1, pp. 112116, 2018.

[6] R. I. DE OLIVEIRA, S. O. SOUSA, F. C. DE CAMPOS (2019). Lean manufacturing implementation: bibliometric analysis 2007-2018, International Journal of Advanced Manufacturing Technology, vol. 101, no. 1-4, pp. 979-988, Mar. 2019.

[7] N. UPADHYE, S. G. DESHMUKH, S. GARG (2010). Lean manufacturing system for medium size manufacturing enterprises: An Indian case, International Journal of Management Science and Engineering Management, 2010.

[8] M. BUCKO, V. SCHINDLEROVA, I. SAJDLEROVA (2020). Application of lean manufacturing methods to streamline the welding line, Manufacturing Technology, vol. 20, no. 2, pp. 143-151, 2020.

[9] Y. DAVE, N. SOHANI (2012). Single Minute Exchange of Dies: Literature Review, International Journal of Lean Tbinking, vol. 3, no. 2, 2012.

[10] P. N. RAJA, S. M. KANNAN (2007). Evolutionary programming to improve yield and overall equipment effectiveness of casting industry, Journal of engineering and applied sciences, vol. 2, no. 12, pp. 1735-1742, 2007.

[11] R. DOMINGO, S. AGUADO (2015). Overall environmental equipment effectiveness as a metric of a lean and green manufacturing system, Sustainability (Switzerland), vol. 7, no. 7, pp. 9031-9047, 2015.

[12] S. SHINGO (1985). A Revolution in Manufacturing: The SMED System, 1st ed. Cambridge: Productivity Press, 1985.

[13] M. Y. SYAFEI, T. LOKADIPATI LS (2018). Improving Work System by Reducing Setup Time Activity in Drying Room in Pharmaceutical Industry with Single Minutes Exchange Die (SMED), JIE Scientific Journal on Research and Application of Industrial System, vol. 3, no. 1, p. 50, 2018. 
[14] K. CHENG, K. MUSTAFA (2016). Managing Complexity in Manufacturing Changeovers, 2016, pp. 1-10.

[15] K. E. CHONG, K. C. NG, G. G. G. GOH (2016). Improving Overall Equipment Effectiveness (OEE) through integration of Maintenance Failure Mode and Effect Analysis (maintenance-FMEA) in a semiconductor manufacturer: A case study, IEEE International Conference on Industrial Engineering and Engineering Management, vol. 2016-Janua, pp. 1427-1431, 2016.

[16] M. L. MULLA, S. G. BHATWADEKAR, S. V PANDIT (2014). Implementation of Lean Manufacturing Through The Technique of Single Minute Exchange Oo Die (SMED) to Reduce Change Over Time, International Journal of Innovative Research in Science, Engineering and Technology (An ISO Certified Organization), vol. 3, no. 6, pp. 13069-13076, 2014.

[17] E. SOUSA, F. J. G. SILVA, L. P. FERREIRA, M. T. PEREIRA, R. GOUVEIA, R. P. SILVA (2018). Applying SMED methodology in cork stoppers production, Procedia Manufacturing, vol. 17, pp. 611-622, 2018.

[18] J. LOZANO, J. C. SAENZ-DÍEZ, E. MARTÍNEZ, E. JIMÉNEZ, J. BLANCO (2017). Methodology to improve machine changeover performance on food industry based on SMED, International Journal of Advanced Manufacturing Technology, vol. 90, no. 9-12, pp. 3607-3618, 2017.

[19] E. OTERO, I. LOPES (2018). Productivity improvement of a production line through quick changeover concept - a case study, Advances in Transdisciplinary Engineering, vol. 7, pp. 897-906, 2018.

[20] S. JEBARAJ BENJAMIN, U. MURUGAIAH, M. SRIKAMALADEVI MARATHAMUTHU (2013). The use of SMED to eliminate small stops in a manufacturing firm, Journal of Manufacturing Technology Management, vol. 24, no. 5, pp. 792-807, 2013.

[21] M. MACEDO FRAIZ, A. ASSAD, F. O. DROZDA (2019). SMED methodology implementation in a manual process: Case study in an industry of the Oil and Gas sector, Journal of Lean Systems, vol. 4, no. August, pp. 121-145, 2019.
[22] P. TAMÁS (2017). Examining the possibilities for efficiency improvement of SMED method using simulation modelling, Manufacturing Technology, vol. 17, no. 4, pp. 592-597, 2017.

[23] I. B. DA SILVA, M. GODINHO FILHO (2019). Single-minute exchange of die (SMED): a state-of-the-art literature review, International Journal of Advanced Manufacturing Technology. 2019.

[24] L. D. GABAHNE, M. M. GUPTA, D. ZANWAR (2014). Overall Equipment Effectiveness Improvement: A Case of injection molding machine, The International Journal of Engineering and Science, pp. 2319-1813, 2014.

[25] M. BEVILACQUA, F. E. CIARAPICA, I. DE SANCTIS, G. MAZZUTO, C. PACIAROTTI (2015). A Changeover Time Reduction through an integration of lean practices: A case study from pharmaceutical sector, Assembly Automation, vol. 35, no. 1, pp. 22-34, 2015.

[26] A. HUARHUA-MACHUCA, V. H. NUNEZPONCE, E. ALTAMIRANO, J. C. ALVAREZ-MERINO (2019). Applying Lean Techniques to Reduce Defective Products: A Case Study of an Electrode Manufacturing Company, in IEEE International Conference on Industrial Engineering and Engineering Management, 2019.

[27] M. HOLWEG (2007). The genealogy of lean production, Journal of Operations Management, vol. 25, no. 2, pp. 420-437, 2007.

[28] E. S. M. DA COSTA, R. M. SOUSA, S. BRAGANÇA, A. C. ALVES (2013). An industrial application of the SMED methodology and other lean production tools, in 4th International Conference on Integrity, Reliability and Failure, vol. 1, no. i, pp. 1-8, 2013.

[29] F. MOREIRA, A. C. ALVES, R. M. SOUSA (2010). Towards Eco-efficient Lean Production Systems Francisco, in IFIP International Federation for Information Processing, pp. 100-108, 2010.

[30] J. D. MORALES MÉNDEZ, R. SILVA RODRÍGUEZ (2016). Set-up reduction in an interconnection axle manufacturing cell using SMED, International Journal of Advanced Manufacturing Technology, vol. 84, no. 9-12, pp. 19071916, 2016.

[31] G. CHAND, B. SHIRVANI (2000). Implementation of TPM in cellular manufacture, Journal of Materials Processing Technology, vol. 103, no. 1, pp. 149-154, 2000. 